\title{
2. Aristotle on Legality and Corruption
}

\author{
Richard Mulgan
}

\section{Defining corruption}

For most people in public policy circles, one suspects, the main problems surrounding corruption are practical. The concept itself is comparatively straightforward and concrete in connotation, referring to certain specific practices such as bribery, cronyism and nepotism. The harmfulness of such practices is taken as self-evident because they are obvious abuses of power. The only question is how to 'stamp it out'.

For a political theorist, however, 'corruption' is a striking and perplexing term. In the first place, it has proved remarkably difficult to define in general terms, beyond a set of leading examples such as bribery, favouritism and nepotism. We may know that it is wrong but we are not quite sure what 'it' is. Experts disagree about what activities are to count as corrupt and about whether activities condemned as corrupt in one political context should be seen as functional in another. Secondly, 'corruption' is a term of unqualified ethical condemnation. To label any person or practice as 'corrupt' is to stigmatise them as beyond the moral pale. It combines the moralism of words such as 'sin', 'evil' or 'wickedness' with added psychological implications of personal depravity and debased character.

This chapter explores the incongruity between these two aspects-between the contextualism and the moralism inherent in corruption-in part through a historical comparison of the use of similar terms by the Greek philosophers, particularly Aristotle.

The problems of defining corruption have been well explored by others (for example, DeLeon, 1993; Heidenheimer, 1970; Heywood, 1997; Philp, 1997). In brief, definitions differ depending on whether they focus on the responsibilities and duties of public office and office-holders, on compliance with law and legally defined standards or more broadly on the clash between illegitimate personal interest and the public interest. While this question can hardly be said to be closed, the most compelling analyses would seem to be those that rely centrally on acting contrary to the common or public interest because it involves the illegitimate pursuit of a private interest (DeLeon, 1993; Philp, 1997). Definitions that depend on compliance with the particular duties of an office or with existing 
legal rules certainly highlight key factors in identifying corrupt political actions by individual politicians or officials. However, by taking existing duties and rules as given, such definitions are too closely tied to a particular institutional context. They do not provide an external standard by which to assess whether the duties or rules themselves prohibit actions that should be regarded as corrupt. If the definition of corruption is widened to include the illegitimate pursuit of a private interest then it allows an independent judgment of precisely what private interests existing ethical standards and rules ought to preclude. Admittedly, the use of a term such as 'illegitimate' is itself question-begging and does not provide an uncontested criterion for ruling selfish acts in or out, which is why the definition of corruption is so contested.

Corruption needs to be understood in terms of its opposite: the condition of soundness or health that either has subsequently degenerated into corruption or at least provides a standard against which the corruption can be identified (Philp, 1997). In J. L. Austin's (1962) colourful description applied to the term 'real', 'corruption' is a 'trouser' word, being filled and shaped by its complementary counterpart. If we want to give an account of political corruption, we should always begin by asking what uncorrupt - that is, sound or healthy - government looks like.

On the definition given above, uncorrupt politics implies that personal or private interests do not illegitimately override the public interest. At the same time, though the public interest should prevail, private interests are not necessarily ruled out altogether, especially in a liberal pluralist polity. Liberal democratic politics, which provides the moral standard against which corruption is typically characterised in present-day discourse, is based on the legitimate pursuit of selfinterest, both by individuals and by sections of the community. True, the rituals of political discourse demand that deliberation about public policy be cast in the language of the public good and that individual or sectional self-interest be suppressed as a reason for acting. At the same time, no-one doubts both the actuality and the legitimacy of political self-interest in liberal democratic politics. To outlaw all self-interested politics would rule out much of the electioneering, lobbying, pork-barrelling and log-rolling on which democratic pluralist politics is premised.

Not that anything goes in the liberal pursuit of self-interest. Liberal pluralism has always adopted some independent, public-interest standards. Some standards are procedural, guaranteeing the political mechanisms by which private interests may compete; others are substantive, limiting the decisions that may be imposed on members of the citizen body. Constitutional and legal rules lay down limits and constraints that competing players must respect. Questions then arise about which types of procedure overstep the line between the legitimate and the illegitimate pursuit of private interests. When does 
lobbying become bribery and when does bargaining become collusion? When does redistributing resources to one's supporters become an infringement of other people's rights? Opinions differ significantly about what types of selfserving action are to be classed as illegitimate and therefore corrupt. Significant examples of such contested areas include making government appointments for partisan advantage (as in the NSW Metherall affair) or receiving payment for asking parliamentary questions (as in the UK scandal cited by Philp, 1997). At a more mundane level, public servants are clearly at odds over what type of gift may be legitimately received from a public client (ICAC, 2001). Possibilities for disagreement are multiplied when concepts of corruption are applied crossculturally, for instance in countries where gift-giving or preference for one's own kin or ethnic group is considered appropriate and legitimate.

For present purposes, the important point is not so much the differences in opinion over corruption in liberal democracies but the premises that underlie such disagreement. Any realistic notion of corruption applicable in present-day liberal democratic politics has to recognise that politicians (and citizens) cannot reasonably be expected to be motivated solely by concern for the common good or public interest. Instead, the concept of the public interest is institutionalised more as a set of minimal side constraints - to adopt Nozick's (1974) useful term - on the pursuit of private interests. A condition of sound - that is, noncorrupt - politics is not a polity where everyone pursues the public interest but one where the pursuit of private interests is not allowed to transgress certain minimal public-interest limits. Where public-interest constraints kick in and force private interests to give way is a matter of dispute. As already noted, the boundary between the legitimate and the illegitimate pursuit of private interests is blurred and contested. More fundamentally, however, the judgment is essentially a balance struck between competing values: the pursuit of individual or sectional interests on the one hand, and concern for the common good on the other.

If sound politics is identified as a compromise between selfishness and concern for the common good, corruption then becomes a matter of tipping the balance too far in the direction of selfishness. Such a nuanced view of where the line is to be drawn between non-corruption and corruption may sit awkwardly with the highly moralistic implications of the term itself. 'Corruption', as already noted, carries very strong moral-indeed, moralising-overtones, redolent of 'evil' and 'sin', suggesting both universalistic standards of right and wrong and a sense of righteous outrage at the practices in question. To label a practice as 'corrupt' is to condemn it unequivocally in the strongest possible terms. And yet, we now discover, corruption is not so much a festering disease in the body politic as a possibly minor imbalance between two legitimate forces in the 
community. 'Corruption' has connotations of moral absolutism (compare with 'swear off the demon drink') whereas, in practice, it seems to refer to striking the right balance ('drink but not to excess').

\section{Corruption in the Greek tradition}

An historical digression can help us explore this issue further. In the history of European thought, discussion of corruption in politics and the possibility of achieving non-corrupt politics immediately suggests the Greek philosophers, particularly Socrates and Plato, but also their immediate successors in the lateclassical and Hellenistic periods, all of whom agonised about the corruption of politics and the corruptibility of politicians. Socrates rejected the life of the politician as incompatible with the pursuit of knowledge and thus provided the inspiration for subsequent philosophies of quietist withdrawal, such as Cynicism, Epicureanism and the more extreme versions of Stoicism that were to flourish in the Hellenistic age. Plato, in turn, while never renouncing the world of politics, nonetheless located it in the inferior realm of his dualistic universe. Politics was relegated to the world of the senses, the world subject to inevitable change and decay (literally: the world subject to corruption). Aristotle, though less contemptuous of the sub-lunar world of change and contingency than Plato, also never abandoned his Platonic commitment to the superiority of an eternal unchanging realm accessible only to pure reason. Human society was inevitably contingent and liable to variation.

These theorists, then, all held to some form of ontological dualism, in which a world of pure truth and goodness stood opposed to an inferior world of uncertainty and evil. In terms of their approach to government and politics, this dualism took one of two forms. The more radical and deliberately paradoxical path, such as that of the Cynics, involved a total rejection of all government, and by implication a rejection of all human society, as irredeemably flawed; the less radical approach followed by Plato and Aristotle was to devise an ideal form of government that would in some way incorporate the other-worldly values of unqualified truth and goodness. This ideal, in turn, provided a standard against which the performance of everyday regimes could be judged and improvements recommended. For Plato, such an ideal is the rule of philosophers, as depicted in The Republic and recalled in later political dialogues such The Statesman (293) and The Laws (711-2, 875). For Aristotle, the political ideal is similarly the rule of the ideally wise and virtuous (Pol. IV 2, 1289a30-2), whether through an outstandingly virtuous individual or family (absolute rule) or through a broader aristocracy of truly virtuous men. 
Plato, in The Republic, describes the contrast between the ideal and inferior states in terms of an imagined 'decay' or 'destruction', using the word pthora (546a), the Greek term later regularly Latinised as corruptio. The ideal state undergoes a number of stages of such decay, through timocracy, oligarchy and democracy, culminating in tyranny, which is the worst regime of all. Elsewhere, the contrast between ideal and inferior is expressed in different images. In The Statesman, for instance, inferior regimes are said to 'mimic' or copy the ideal constitution (301a, 303c), an image often used by Plato in his epistemology to represent the relationship between the inferior objects of the senses and the objects of true knowledge. Aristotle, in The Politics, uses different terminology again, 'correct' (orthos) for the good forms of government and 'deviations' or 'perversions' (parekbaseis) for the inferior. The implication is in all cases the same: the ideal form of government is conceived as logically prior, and inferior constitutions are defined in relation to it, as being in some sense lacking or deficient.

There is thus a close parallel with the modern concept of political corruption understood in terms of the absence of sound or non-corrupt politics. In Greek, however, the equivalent term to 'corruption' (pthora) retains more of its literal meaning and implies actual decay or disintegration. In Aristotle, pthora is the standard philosophical opposite of genesis or 'coming into being' and in The Politics its main use arises in connection with the destruction of particular constitutions (Bonitz, 1955). In modern English, on the other hand, the metaphor of organic decay is less prominent. We talk of corrupt regimes without necessarily implying that they have degenerated from a former healthy condition. In this respect, corruption is closer in meaning to 'deviant', the term Aristotle himself uses to describe inferior constitutions.

For both Plato and Aristotle, the key feature that the ideal regimes possess as a result of their wise and virtuous rulers is that they are governed in the common interest. Conversely, the leading characteristic that distinguishes deviant regimes from the ideal is that their rulers rule in their own interest rather than the common interest. In The Republic, the guardians' training and communal living lead them totally to suppress any notion of self-interest and to find their personal fulfilment in the happiness of the whole $(420 \mathrm{~b}-421 \mathrm{c})$. The imagined corruption of the ideal state and its decline to tyranny through descending stages of moral degradation can be read as a gradual assertion of individual self-interest and a retreat from commitment to the common good. Aristotle gives even more prominence to the contrast between pursuit of the common interest and self-interest, making it the only criterion defining the difference between correct and deviant constitutions: 
The correct forms of government are those in which the one, the few or the many govern with a view to the common interest: but the governments which rule with a view to the private interest whether of the one, or of the few or of the many are deviations (Pol. III 7, 1279a28-32)

Aristotle initially allows three types of correct constitution-namely kingship (rule of one), aristocracy (rule of few) and polity (rule of many) - all in the common interest. Later, however, he concentrates on two varieties: absolute kingship, the (largely hypothetical) rule of one outstandingly able man, and aristocracy, the regime where power lies with a citizen body consisting of virtuous men of property. The third correct option, polity-rule by a virtuous majority - quickly slips down the ranking. A majority of citizens are capable of only a limited, military-style virtue (Pol. III 7, 1279bl-2) and polity becomes a somewhat deviant constitution, better than oligarchy and democracy but not fully correct and therefore, by implication, not fully governed in the common interest (Pol. IV 8, 1293b22-7). Rule in the common interest rather than in the interest of the rulers remains the touchstone of a correct regime. Aristotle's account of political deviance thus resonates again with modern analyses of political corruption: both establish a nexus between political deviance and the rulers' pursuit of their own private interest against the common interest.

However, despite this conceptual parallel, the ancient and modern views of political corruption exhibit important differences. One such difference concerns the practicality of achieving non-corrupt politics. In the modern conception, corruption is seen as remediable, at least at the systemic level; the best existing regimes, such as those at the top of the Transparency International (TI) table, are considered to be largely free of corruption. Though corruption, like crime, will never be totally stamped out, it can be relegated to the margins as it has been in many present-day polities. In particular, from the perspective of developed donor countries like Australia, political corruption is mainly a problem for 'messy' or 'failed' states, such as Indonesia or Papua New Guinea. Even where more systemic corruption is evident, as in Australian State police forces, such practices can be interpreted as intolerable pockets of corruption to be stamped out by anti-corruption agencies and mercifully absent from other branches of government.

For Aristotle, however, as for Plato, all existing regimes fall on the corrupt or deviant side of the corrupt/non-corrupt line. Plato certainly considered his philosopher's city to be beyond practical reach; he may have intended it to be impossible even in principle. His ideal state in The Laws makes more concessions to human frailty but is still clearly an unachieved ideal that is most unlikely ever to be put into practice. In a similar vein, Aristotle considers absolute rule to be practically impossible (Pol. VII 14, 1332b, 2207). Even his ideal aristocracy, which contains everything one could wish for but nothing impossible (Pol. VII 
4, 1325b38-40), though in principle attainable, is an imagined ideal - not a realistic possibility. The function of the ideally best constitution was to provide a moral contrast with the inferior specimens of everyday experience, not to provide some model of constitutional 'best practice' to which struggling nations and failed states should be expected to aspire as a condition of receiving loans from richer countries.

This difference in practicality is also reflected in differences over the meaning of corruption. Modern notions of corruption, as already noted, concentrate on the illegitimate pursuit of self-interest in preference to the common interest. In this respect, they establish a balance between the pursuit of public and private interests and do not require governments (or citizens) to be completely dedicated to the common interest. By contrast, Aristotle, like Plato before him, did require such complete dedication. Ideal, non-corrupt states are governed by ideally virtuous rulers who are wholly focused on the common interest and would never consider pursuing their own interests at the expense of the good of the community. Aristotle's ruling aristocrats had their own private lives and personal interests, but insofar as they acted politically they would be wholly devoted to the good of the polis. In this respect, the ancient accounts, though more utopian, may be said to be more in tune with the moral absoluteness implicit in the concept of pure, non-corrupt government.

On the other hand, if the standard of non-corrupt government is placed so high as to be unachievable, it could be argued that such conceptual purity is bought at too high a price. In particular, if all regimes are essentially corrupt because all are ruled in the interest of the rulers, what becomes of the distinctions that we want to make between corrupt and non-corrupt regimes, between Finland and Nigeria or between New Zealand and Indonesia? If all are corrupt, what is the point of condemning corruption?

For Aristotle, as for Plato, the fact that all existing regimes are deviant because all are governed in the interest of the rulers does not mean that all are equally deviant. Such a categorical conclusion may have been drawn by the more radical anti-political philosophers, such as the Cynics and Stoics. But both Plato and Aristotle, and particularly the latter, were interested in distinguishing between varying degrees of deviance in everyday politics. That is, the model of the ideal, correct state was used not only to criticise all everyday regimes as fundamentally flawed but also to provide a standard against which everyday regimes could be assessed and found more or less deviant.

Here the key factor was the rule of law. Rulers might all be self-interested, whether they were single rulers (tyranny), the rich few (oligarchy) or the poor majority (democracy). But their rule could be better or worse, depending on whether they were constrained to act within the law or whether they were free 
to follow their wishes. Plato makes the case most compellingly in The Statesman in the context of an argument intended to highlight the weaknesses as well as the strengths of the rule of law (291-300). Law is deficient because rules are blunt and circumstances varied. The true professional, such as a skilled doctor, is not bound by the instructions left for subordinates but assesses each case on the basis of individual judgment. So too the true politicians - the philosopher rulers - will not be bound by general laws but will judge each issue on its merits. However, while the constraint of law curbs the wisdom of the philosopher, it also serves to restrain the selfishness of the ordinary ruler. Amongst inferior regimes that lack the benefit of having philosophers as their rulers, those governed in accordance with law are all superior to those where rulers can rule as they wish. The theme of the value of the rule of law in curbing the self-interest of rulers is developed in much more detail in the dialogue The Laws and was also taken over by Aristotle, who uses it as a major criterion in distinguishing between more moderate and more extreme versions of inferior constitutions.

Aristotle, too, recognises that the bluntness of law can create problems and also that laws themselves may be unjust if they are the product of an unjust regime (Pol. III 11, 1282b12). Yet lawful rule is on the whole better than lawless rule, because all laws are general and therefore to some extent impartial and a curb on the rulers' self-interest. Ordinary people who are called on to make decisions in particular cases are too likely to be carried away by feelings of friendship or hatred and to be blinded by personal pleasure and pain (Rhetoric I 1, 1354a34b11). This argument is summed up in the famous epigram that 'law is intellect without desire' (Pol. III 16, 1287a32). Thus, in each case, the most extreme and worst forms of oligarchy (Pol. IV 6, 1293a30-1), democracy (Pol. IV 6, 1293a810), and tyranny (Pol. IV 10, 15-23) are characterised by the absence of the rule of law, whereas the more moderate and more stable are ruled in accordance with law.

Aristotle's argument for the rule of law does not depend on the content of the laws so much as on the nature of any law. Laws themselves can be partial and unjust in their intent. Indeed, all laws in deviant regimes are inevitability skewed in the interest of the ruling group. What makes the rule of law superior (or less inferior) is that any law impartially applied must reduce, though it will not eliminate, the personal benefits that rulers derive from decisions. For instance, laws in an oligarchy will always favour the wealthy and propertied and will always penalise the poor and property-less. But at least the wealthy will be treated equally with one another and in accordance with legal precedents; rulers will not be able to make unpredictable, ad-hoc decisions to suit themselves.

Again there is a parallel with modern accounts of corruption in which legality or the rule of law is sometimes taken as a defining feature. Corruption is often 
equated with breaking the law for the sake of securing a personal advantage. Anti-corruption campaigners are therefore always putting their weight behind greater respect for the rule of law. However, as already noted, such a conception of corruption is question-begging in that it does not stipulate what types of selfinterested action should be considered corrupt and therefore illegal. For instance, a case can be made that some lawful activities, such as corporate contributions to campaign funds, involve an illegitimate pursuit of self-interest and should therefore be outlawed as corrupt. That is, a conception of corruption that is grounded in existing law is open to charges of circularity or moral relativism because it offers no independent standard of what should count as corrupt.

Aristotle, however, avoids this difficulty because he is assuming that all regimes, lawful and lawless, are deviant and unjust, though to varying degrees. He is not, at this point, trying to draw a line between sound and corrupt regimes or between just and unjust laws. He therefore does not face the issue of an independent ethical standard implicit in the modern use of corruption. That issue has been dealt with elsewhere, in the conception of the correct (and unattainable) constitution. Here, he has a more modest aim: simply to mark out a means by which the harmful effects of self-interested (and corrupt) rule may be mitigated. Self-interested rulers constrained by law will deviate less from the standard of good government and do less harm than the same rulers unconstrained by law. The rule of law is thus not overburdened with any moral connotations of being linked with the concept of uncorrupt government. In this case, the question of whether particular laws are good or bad can be more safely left to one side. The main point is that keeping within any law, whether good or bad, will be better and less corrupt than allowing self-interested rulers the freedom to disregard the law at will.

Aristotle is similarly pragmatic in his advice about how best to ensure that members of the ruling groups rule in accordance with law. General commitment to the values of the regime is a key component, to be achieved through public education (Pol. V 9, 1310a14-18). But equally important are socioeconomic factors. Citizens who must give most of their energy to making a living will take little interest in politics and will therefore be content to let the law take its course rather than try to impose their own solutions (Pol. IV 6, especially. 1293a17-19). Hence, the most law-abiding form of democracy is one where the people are predominantly agricultural without the time or incentive to come into town to attend meetings. The rule of law is under most threat either from the idle rich, with the leisure to use government to enrich themselves still further, or from the indigent urban poor who also have both the time and the incentive to make decisions in their own interests. Those of moderate wealth, on the other hand, can generally be trusted to be law-abiding (Pol. IV 11, 1295b2-34). 
Aristotle's insistence on the importance of law - any law - in reducing the incidence of political corruption does not provide a defining mark for corruption. Nonetheless, it may be instructive for modern debates about corruption. It resonates, at least, with the practical focus in much anti-corruption work on the importance of preventing government officials from breaking actual laws for personal gain. Most anti-corruption campaigns are concerned with breaches of actual laws and regulations, regardless of the actual content of the laws and regulations in question and regardless of whether such laws and regulations are justified. True, this point begs the broader and more fundamental question about what types of self-interested activity should be treated as corrupt and therefore made the subject of anti-corruption laws and regulations. But for the most part, laws and regulations are taken as given and the task is simply to make sure that those in positions of power and responsibility uphold the law as it stands and are not tempted into breaking it for their own private benefit. Indeed, it is for this reason that many modern accounts of corruption adopt illegality as a defining feature of corruption. Thus, both ancient and modern perspectives agree on the importance of rulers ruling within the law, whatever the law may be. The ancients viewed this more as a task of reducing the inevitable corruption or deviance of all governments, whereas in the modern view the issue of legality marks the difference between corrupt and non-corrupt governments.

\section{Structural weakness and moral failure}

So far, we have found reason to criticise modern notions of political corruption because they either do not provide a clear account of what should be considered corrupt/non-corrupt politics or, if they do attempt such an account, inappropriately apply a term of absolute moral condemnation to what is in practice a realistic balance struck between self-interest and the common interest. Aristotle avoids these objections, because the equivalent term for political corruption is clearly applied to all non-perfect regimes and is not used to draw a line between the more or less imperfect. Corruption becomes a matter of degree, a characteristic essential to all existing regimes.

The focus of discussion has been at the general level of the regime as a whole, in the attempt to distinguish a corrupt from a non-corrupt polity. Yet corruption can also be approached at the individual level, from the perspective of the individual politician or official who may or may not break a particular law or code of conduct for personal gain. In this context, the language of moral absolutes appears less inappropriate. We talk often of people of 'total honesty' or 'unimpeachable integrity' who would never 'cross the line' to commit a corrupt act. In such individualised contexts, judging the behaviour of, say, individual tax officers or individual police, black-and-white moralising descriptions such 
as 'honest' or 'corrupt' seem wholly appropriate. They indicate an assumption that there are important ethical standards which individuals can reasonably be expected to uphold.

Moreover, breaching such standards for personal gain marks an abhorrent betrayal of public trust. In contrast with the collective perspective, judging individual corruption in terms of existing law seems less question-begging. Individual officials cannot be expected to set the standards for themselves and so are appropriately judged in terms of the rules set for them. Entire governments, on the other hand, are properly judged not just on whether their rules are complied with but also on whether they have set the right rules - a much more nuanced judgment where terms such as 'corruption' may be more contestable.

Note that a judgment of individual corruption, although couched in the strongest moral terms, is very context specific. This is not to say that the person concerned is wholly depraved or, more importantly, that the persons not so condemned are moral paragons, wholly dedicated to the common good in all their actions. All it means is that, in relation to the specific range of professional ethical demands that most people can be expected to meet, a particular individual has failed to measure up, and culpably so. For this reason, the sense of moral condemnation implicit in the label 'corruption' is strongest within a context of everyday compliance. We are most comfortable in the allocation of moral blame if the individual has been surrounded by non-corrupt colleagues and therefore has had every encouragement to stay on the right side of the line. By contrast, in contexts where corrupt behaviour is endemic, the very use of the term 'corruption' to describe such individual acts appears more questionable. The behaviour in question is much less obviously due to individual moral weakness but is more a matter of institutional structures and social norms, as Aristotle recognised. For individuals, avoiding corruption is not meant to set heroic ideals, but rather a basic level of honesty that only the very weak or wicked will fall beneath.

Judgments of individual corruption therefore appear less problematic than those made of whole governments, particularly insofar as they take existing standards and general compliance with such standards for granted. Of course, collective assessments of corruption can be made in terms of the amount of individual corruption that occurs. Country A may be less corrupt than Country $\mathrm{B}$, not because its government is more concerned with the common good, but because fewer politicians and officials are on the take. Indeed, most collective assessments, such as those conducted by TI, seem to be of that type. It is for this reason also that definitions of corruption so often concentrate on actual illegality or the duties of an actual office - definitions that fit the individual case much more than the collective. 